\title{
Conducting photo methodologies: framing ethical concerns relating to representation, voice and data analysis when exploring educational inclusion with children
}

\section{Clare Woolhouse*}

Senior Research Fellow, Faculty of Education, Edge Hill University, St

Helen's Road, Ormskirk, Lancashire, L39 4QP, UK.

Tel: 0169550 893, Woolhouc@edgehill.ac.uk

This article is a critical discussion regarding a photo elicitation research project.

In the project children and young people studying in primary, secondary and special schools were invited to explore their experiences of inclusion and exclusion by taking photographs of their everyday activities. These photographs were cartoonised to protect identities and then shared with other children and young people.

This paper offers a detailed description of the methodological approach adopted, before discussing three key aspects relating to the ethical issues that emerged. The first aspect is an exploration of the concerns and challenges posed by adopting a photo-elicitation method with children and young people. The second area concerns possibilities for accessing individual's perceptions and respecting the differing 'voices' of research participants, The third aspect involves a reflection upon the advantages and difficulties of conducting data analysis on visual materials. Drawing these three aspects together it is concluded that while photo-elicitation with children is not without its challenges, the approach provides a multimodal route for accessing and sharing multiple and varied voices, some of which are too often deprived of a platform.

Keywords: photo elicitation, qualitative methodology, inclusion 


\section{Introduction}

This paper details a photo elicitation research project which is documenting children's experiences of inclusion by exploring their views, their relationships with others and the educational spaces they inhabit. At the start of the project children and young people attending primary, secondary and special education schools in the North West of England and Isle of Man were asked to take photographs during their everyday school activities, inside and outside the classroom, that they felt represented inclusion or exclusion. These photographs were then shared with other children and young people and with teacher trainees, practitioners such as teachers and teaching assistants, and academics. The aim of this process was to adopt an approach that was pedagogically ethical and inclusive, one that could access different perspectives about inclusion by comparing variations in conceptual understandings and their application in educational settings ${ }^{1}$. This paper reflects upon the specific ethical issues that arose in the first phase of the project that involved accessing the views of children and young people.

\section{Setting out the research context}

The right to inclusive education is enshrined in article 24 of the UN Convention of the rights of persons with disabilities (UN, 2006). Such rights are also acknowledged in key educational policies currently operationalised at local and national level in the UK, with documents making reference to the common principles of inclusion, social justice, equitable education systems and the responsiveness of schools towards diversity (i.e. Children and Families Act, 2014; DfE, SEND Code of Practice 2014). However, research published over the past few years considers the difficulties with developing inclusive practices within various UK educational settings (Ainscow et al., 2012; Hallett

\footnotetext{
${ }^{1}$ Papers have been published relating to the methodology and initial findings of the photoelicitation project (Dunne et al., 2017; Woolhouse et al., 2017).
} 
and Armstrong, 2013; Hodkinson, 2012; Lauchlan and Greig, 2015; Nind et al, 2012; Norwich, 2013; Slee, 2011; Young and Florian, 2013). The difficulty of advancing inclusion is not confined to the UK, and there are complexities and daily challenges which practitioners face in enabling inclusion in diverse classrooms, globally. International research has particularly drawn attention to issues with teacher effectiveness and teacher welfare, calling for targeted professional development and a rethinking of what constitutes inclusive practices (Allan, 2010; Armstrong et al, 2009; Cowie and Khoo, 2017; Forlin, 2012; Krull et al. 2014; Mitchell, 2014; Smyth et al. 2014; Whitburn 2016). In response to such calls for greater attention to inclusion, concerns have been raised with how inclusion is defined. There has been an acknowledgement that the concept of inclusion is 'slippery' (Atkins, 2016:7) and contested, with Adderley et al. (2015:108) arguing that inclusion is fluid and changing, occurring at "the interface between teacher and pupil, pupils and peers, and pupil and school environment".

Taking a different stance, other researchers have questioned the use of inclusion as a term, warning that it cannot be "reduced to a set of strategies or inspection criteria" (Atkins, 2016:8) as this risks investing control and power with those who design, structure and deliver inclusive practices, while dis-investing and emasculating those who are the subjects of such practices (Hodkinson, 2012; Whitburn 2016). Indeed, Hodkinson (2012:7) has argued that some choices which are defined as inclusionary are actually influenced by "regimes of accountability and the marketization of education ... mediated by notions of classroom sensibility and conformity which seemingly override notions of children's rights". While concerns over defining what constitutes inclusive practice are well founded, the need to rethink and facilitate supportive learning opportunities for all require some understanding and a working definition. Booth and 
Ainscow (1998:2) suggest a broad definition to include all those who might experience marginalisation, rather than aligning inclusion solely with educational needs:

Inclusion or exclusion are as much about participation and marginalisation in relation to race, class, gender, sexuality, poverty and unemployment as they are about traditional educational concerns with students categorised as low in attainment, disabled or deviant in behaviour.

Drawing upon this definition, it would seem that rather than thinking of inclusive practice in education as a tangible thing to be rigidly defined, it is more helpful to think about how to value individuals and their views while encouraging a sense of involvement and membership. To accomplish this, there is a need to question conceptualisations and formulate a way of understanding inclusion that counters the dominant routes of power and foregrounds the perspectives of children and young people about what it means to them to be included. This might be achieved by exploring day to day experiences, in order that researchers and education practitioners can better grasp how "abstract and contested concepts become embedded in the relational, temporal and spatial dimensions of teaching and learning" (Prosser and Loxley, 2007:58). Such research is not intended as a criticism of schools or those working with children, but as a way to better understand the often unheard experiences of children (Slee, 2011; Morgan and Sengedorj, 2015). Taking this stance, the four researchers involved in the research discussed in this paper sought to better understand a range views about inclusion and inclusive practices by investigating how these contested concepts are experienced in educational settings.

To do so, a participatory method that could actively engage children and young people to gain insight into their views, while meeting the appropriate ethics and codes of practice was needed (for examples see Flewitt, 2005; Pope et al., 2010; Morrow, 2008). The possibilities for utilising ethnographic or practitioner research, interviews or 
focus groups were discussed, but with backgrounds in Special Educational Needs (SEN) all four researchers have a preference for using multimodal visual methodologies. Kress and van Leeuwen (2001) and Wiles et al. (2011) advocate a multimodal approach, arguing that utilising different aspects of data production and collection that use images, spatiality or tactile experience can enhance the agency of those involved in creating meaning. As Kress (2011:237) points out; "multimodality focuses on the material means for representation; the resources for making texts (and thus meaning) ... that go beyond language". Multimodality can be adapted in different ways and it is used in our research to develop a visual method of data collection (photo-elicitation), which actively involves participants in the various stages of data production and analysis.

\section{Visual methodologies and photo-elicitation}

Visual methodologies are located within a constructivist and interpretivist paradigm (Spencer, 2011:36-58), utilising images to explore what individuals think and feel about a topic, issue or experience. These methodologies can provide a way to elicit personal views and provide a route for accessing different types of data, such as the emotional responses of individuals to situations, because, as Harper (2002:13) indicates, visual methods "evoke a different kind of information" and "connect an individual to experiences and eras even if the images do not reflect the research subject's actual lives".

One such methodology, and the one deployed in this research is photo-elicitation, an established vein of visual methodology research (Boxall and Ralph, 2009; Prosser and Loxley, 2007). This method can be a means of documenting contrary or unexpected discourse around a topic, and so can facilitate consideration of concerns that may not be on the researchers' radar; thus adopting this method can make the 'taken for granted' visible (Allen, 2011). By seeking out the way in which meaning is co- 
constructed using visual representations, discoveries can be made about how images “embody and enfold people into particular ideologies" (Stockall, 2013:31). Inviting individuals to produce, as well as comment upon, visual representations can be considered a participatory method that also provides an opportunity for self-expression, assisting people in telling their stories with pictures. It is one way to access life experiences and educate researchers with regard to participants' wisdom (Collier and Collier, 1986; Sensoy, 2011).

Photo-elicitation methods where children produce photographs and annotate them can be particularly beneficial when working in areas of inclusion and social justice, as these methods may suit those for whom linguistic communication is more complicated because of their age, a physical disability or language difficulties or those who have an affinity with visual learning (Cowie and Khoo, 2017; Hartley and Allen, 2015; Prosser and Loxley, 2007). In designing the process of the data collection, we engage with the work of Woolner et al. (2010:8) who suggest that inviting children to annotate photographs can be emancipatory and collaborative since "stakeholders are offered the opportunity to voice their opinions and their various perspectives (can be) explored". Such an approach is appealing, it can accommodate contrasting views providing space for children to 'have their say' via a non-verbal method, and can build a more complex picture of the perspectives around inclusion from those it might affect (Thomson, 2008; Todd, 2012). Working with annotated photographs that children and young people produce might be "deemed high risk" (Pope et al., 2010:304) since researchers needs to ensure that each photographer really understands the purpose for which the photographs will be used and provide written, informed consent. Risks might also be associated with the content children choose to photograph, however, in the case of this research it was felt that the children needed to be trusted and given the freedom to express their 
experiences via photographs without the explicit involvement of their teachers or the researchers. Indeed, it was accepted that this approach could offer different insights, by engaging with children as active and capable participants, asking them to identify what is important to them:

"putting cameras in people's hand empowers them in a way that buries the issues of acquiescence and compliance frequently raised in other forms of research ... it allows people the opportunity to exercise choice as competent participants in the research process". Booth and Booth (2003:432)

While the use of photo elicitation might not necessarily eliminate inequities and always empower research participants, this is certainly an aspiration for choosing a methodology that can be responsive to differing situations, with children making decisions on the level and type of engagement they have.

\section{Data collection}

Given that the aim of the research was to elicit the perspectives and experiences of children and young people, the researchers had a responsibility to ensure that those who were involved understood their engagement. Parental and school permissions were initially established with four schools: one primary special, one primary mainstream, one secondary mainstream and one secondary mainstream with specialist provision, who were all part of an existing University-School network. A member of the research team visited each of the schools, meeting with a designated contact and spent time with each class. The project was introduced and the children were encouraged to talk about ideas such as inclusion and belonging in an age appropriate and accessible format so that the children and young people really understood and were able to discuss the basis and aims for the project. The aims of exploring different experiences, views and opinions about inclusion were explained and guidance on ethical issues relating to taking photographs was provided verbally. It was also explained that the photographs 
would be anonymised before being shared with other children, their teachers or researchers. The guidance and consent documentation used in the schools is attached in Appendix 1.

In order to avoid only the most confident and articulate children volunteering, a disposable camera (with 24 shots) was left with four classes (two in the specialist primary school and two in the mainstream secondary school) and the children and young people were asked to gather images during their everyday activities that represented for them inclusion or not. The cameras could be taken away from the classroom so that anyone could select a topic for each image without the researcher, their teachers or parents being present. The children were instructed to take a couple of photographs and then pass the camera to a classmate. Control of the process was with the children themselves. The aim was to make involvement in research fun (Carrington et al. 2010), demonstrate the trust of the researchers and teachers, while respecting that all who wanted to engage were fully capable of making independent decisions about how to share the cameras and visually express their views.

Disposable cameras were used so that the photographs could not be seen by anyone or digitally altered once taken. Once the cameras were returned to the researchers, we printed out the images and shared them with the self-identified photographers, who were asked to reconfirm their consent, before explaining (verbally and/or in writing) what these images meant to them, to offer a window into their worlds for adult 'outsiders'. We asked "is this a representation of inclusion or exclusion? Why do you think this?" The children and young people also provided a small amount of demographic information (gender, age, type of school they attended and whether they identified as having an educational need) (see Appendix 2 to see how this information 
was recorded in phase 1). An example of how the photograph and comment data was recorded for further analysis is shown in Figure 1.

Figure 1: Photo Record sheet from Phase 1 data set

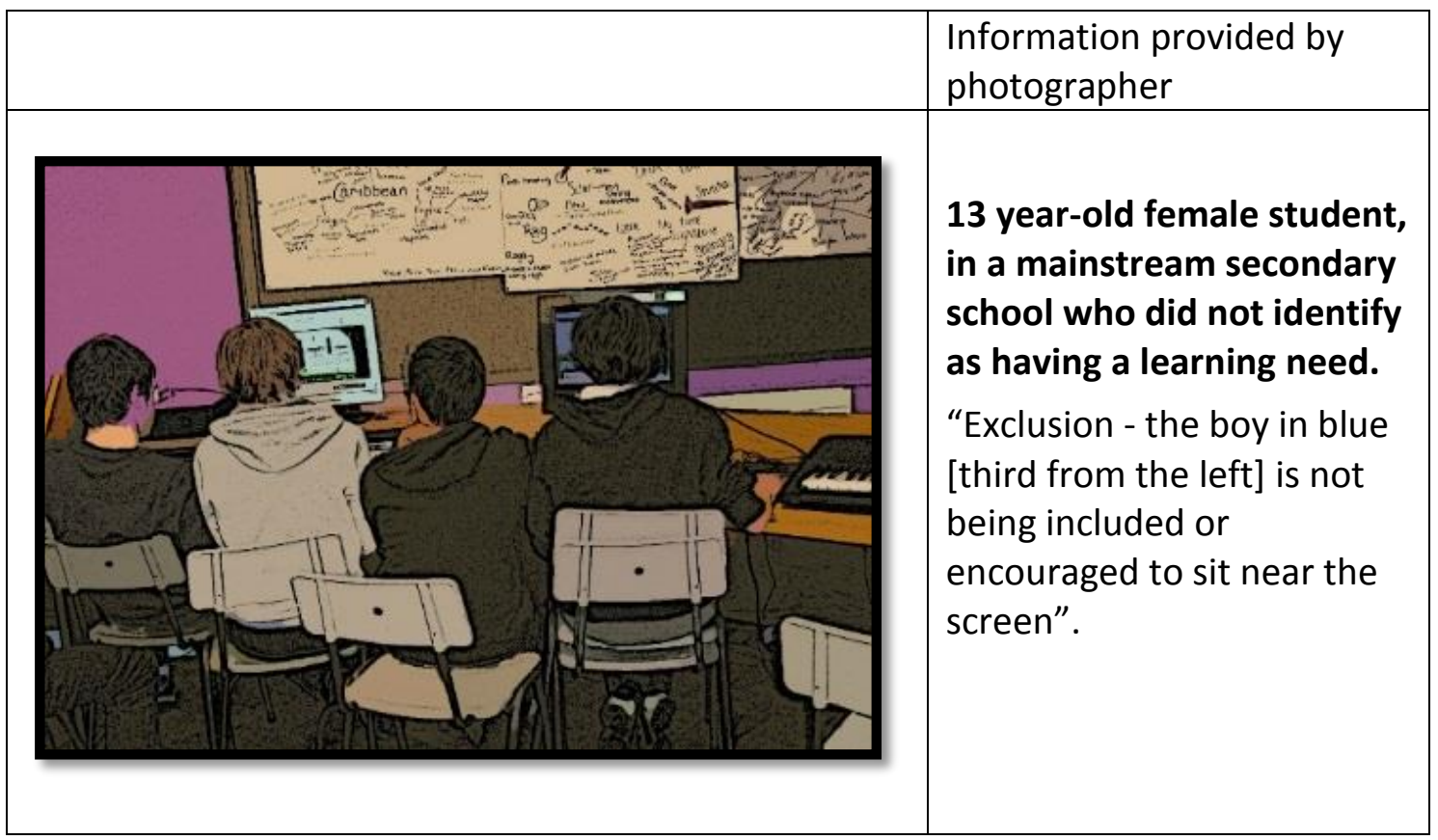

An archive of photographs was created to form an innovative data source for exploring inclusion with a range of individuals including other children and young people, teacher trainees, practitioners such as teachers and teaching assistants, and academics. The aim of the process was to adopt an approach that was pedagogically ethical and inclusive, one that could access different perspectives about inclusion by comparing variations in conceptual understandings and their application in educational settings.

Originally 63 photographs were produced, but it would have been impractical in terms of time to try to share all these. In some cases similar images were taken by different children, or in similar settings and so an 'exemplar' was selected. In trying to edit the collection further, the four researchers spent an extended period of time reviewing and discussing each photograph in turn, exploring our reactions to them. We 
tried to select the ones that were felt to be powerful, provocative or troubling in some way, in that they invited us to rethink our own views of inclusive practice. While this eliminated some of the children's photographs, the intention was to explore differing and difficult perspectives and experiences, rather than find a 'right' way to 'do' inclusion. Eventually the photograph archive was edited to comprise of thirty images, although the intention for the next stage of the research is to share all 63 images with groups of children and their teachers with a further eight schools.

The selected thirty images became the stimulus for discussion. It was important to alter the photographs to reduce the chance that an individual or school setting could be identified when they were shared, while also portraying the photographers and the children who were pictured authentically (Phelan and Kinsella, 2013; Pope, 2010). We tried blurring just the faces of those pictured or covering the faces with a black strip but found neither approach comfortable since the process appeared exploitative and objectified the individuals pictured. In the end, each photograph was scanned and cartoonised using a software package in an attempt to retain dignity while also protecting the identity of those featured, as recommended by Pope et al. (2010) and Wall et al. (2013). While this is not ideal, it offers a fictionalised and hence safer space within which individuals can discuss real-world examples. It is also felt that children are familiar with the process of altering photographs given the wide range and popularity of phone applications that do this.

The cartoonised photographs were then shared with a further group of children and young people (the participants' peers) from alternative, but matched schools. Following a similar process to that used in the original schools, the researchers visited the matched schools to offer explanations of the project and gain informed consents from the schools, parents and pupils. The children and young people were given copies 
of the cartoonised images without the original photographer's comments and were asked to record their responses to the same questions as the original 'photographer' groups: Does this image represent inclusion or exclusion? What do you think about the image? What do you think those in the photo are saying? What do you think they are thinking if this is different? These questions draw on the ideas of Wall, Higgins and Packard (2007) who explore the possibilities for using blank speech or thought bubbles alongside photographs to compensate for unequal power relationships between teachers, researchers and children. Speech or thought bubbles invite individuals to discuss what should go in the blank spaces and suggest it is permissible for this to counter what they think teachers or researchers want them to say. Although this format was designed by Wall et al. (2007) to enable children to reflect on teaching and learning experiences, it was felt that the approach could be adapted to provide a space for children involved in the photo-elicitation project to respond as they would wish. The children's responses were typed up for the data set (see Figure 2).

Figure 2: Photo Record sheet 2 - matched school

\begin{tabular}{|l|l|}
\hline & Photographer: \\
\hline & $\begin{array}{l}12 \text { year old girl based } \\
\text { in a secondary school, } \\
\text { who did not identify as } \\
\text { having educational } \\
\text { needs. } \\
\text { She said: } \\
\text { "Using your mobile } \\
\text { phone to keep other } \\
\text { people out. Secrets." }\end{array}$ \\
\hline
\end{tabular}


Comment from matched pupil:

16 year old female student who did not identify as having learning needs:

"Inclusion - looks like friendship, not forced or organised".

Research findings have been reported (Dunne et al., 2017; Woolhouse et al., 2017) and the aim of this paper is to explore three key ethical issues that arose. The first section provides an exploration of the various issues and challenges that relate to adopting a photo-elicitation method with children and young people. The second area concerns possibilities for accessing diverse perceptions and respecting the differing 'voices' of research participants. The final aspect is a reflection upon the advantages and difficulties of conducting data analysis on visual materials.

\section{Ethical dilemmas: photo-elicitation, diverse perspectives and data analysis}

\section{Children using photo methodologies}

Photo-elicitation was considered to be a particularly ethical methodological choice.

Firstly, the research sought the views of children and young people, many of whom self-identified as having an educational need, so it was important to facilitate and value their personal interpretation in order to access their embodied and material manifestations of meaning production. As Allen (2011) has argued, photo methodologies are particularly effective in controversial areas of investigation, as they can be a means of documenting official and unofficial discourse around a topic, and can raise 'insider' concerns, thus making the invisible, visible. In asking children and young people to independently take the photographs, it was anticipated that the issues and interests that were pertinent to them would be the focus, rather than investing control and power over the choice of topics with teachers or researchers (Morgan and Sengedorj; 2015; Wall, 2017). The aim was for the process of creating and discussing 
the photographs to present the experiences of children and young people themselves rather than re-producing adult-centric perspectives.

A concern with using photo-elicitation was that the children might create photographs and offer comments that they felt would meet the expectations of either their teachers or the researchers, as noted by Joanou (2009) in his work with street children in Peru. However, we address children and young people as media aware digital natives (Palfrey and Gasser, 2013) who can recognise how inclusion is usually represented and/or practiced within schools. Those who produced the photographs did not appear to reiterate stereotypical images and the comments offered were often challenging or thought provoking, and at times contrasting as in the 'Baking' example in Figure 3.

Figure 3: Photo Record sheet for 'Baking' image

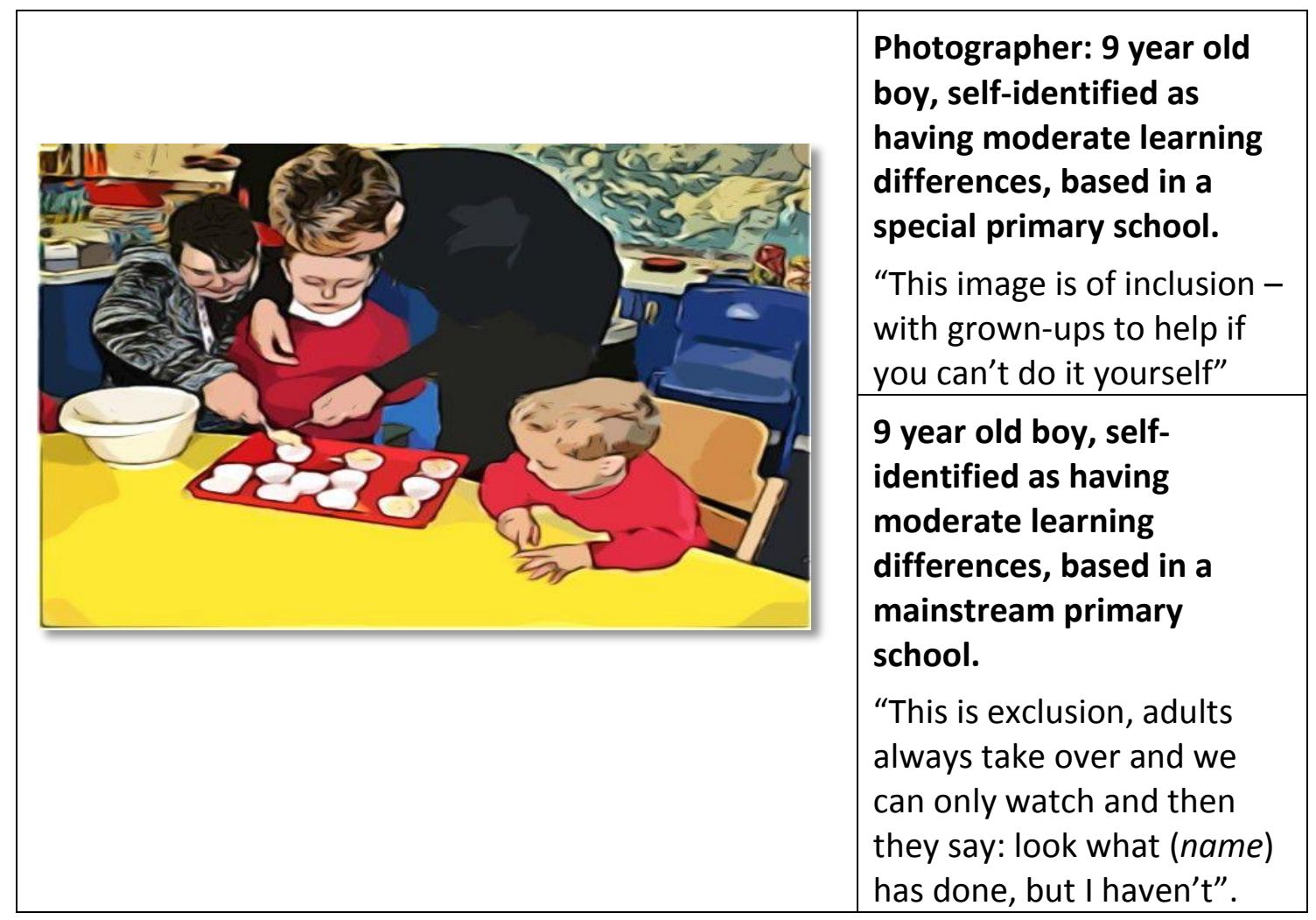


The differences in the two boys' descriptions of Figure 3 can be interpreted as situated in the schooling context with which they are familiar. The original photographer is in a specialist primary school where specialist provision is common and needed by many children, and he may therefore interpret the additional support shown as necessary and beneficial. In contrast, the child from the mainstream setting may only have his own experiences to draw upon as signified by the use of his own name and ' $\mathrm{I}$ ' in his comment. The differing responses from the boys also suggest that while they may be aware of the discourses about inclusion that are utilised by the adults around them, they are perfectly capable of forming views based on their own knowledge and experiences. They are not colonised by the discourses of inclusion (Atkins, 2016; Dunne, 2009; Whitburn, 2016), but are able to re-appropriate them, responding to how they are perceived and treated by adults. In the case of the second boy from the mainstream setting, his emotive response brims with the frustration and resentment of a child who feels isolated in his setting, who both experiences and wants to challenge a lack of agency and control over his own schooling. Through their comments the boys explore and problematize experiences of 'being included', remove the shackles that define them in deficit terms (Hodkinson, 2012), and open up a space for others to learn from them. The example in Figure 3 particularly demonstrates why the photographs needed to be created and annotated by children rather than the images being produced or interpreted by adults, or being left to speak for themselves. The dialogue they invoke are child-initiated and might be seen as a 'challenging starting point for the creation of more inclusive practices in schools" (Messiou, 2006:314). The comments offer contrasting and equally valuable insights into the worlds of different children.

The level of choice afforded to the photographers was a deliberate decision that placed control over the process in the hands of the children and young people, and this 
proved challenging. Initially the plan had been for ten schools to be involved in taking photographs. Unfortunately a number of schools were uncomfortable in using a method that required individuals to take photographs, often of other children and young people, possibly aware that this might be perceived as a safeguarding risk (Blyth and Solomon, 2012; Nutbrown, 2010). In four cases, the schools chose instead to be involved in the later part of the study where the cartoonised images were discussed with groups of pupils to draw out ideas about, and problems with, educational inclusion. Despite the challenges, it was felt that the concerns of school staff were manageable and outweighed by the benefits of asking children to take photographs or discuss the cartoonised images, since this multimodal approach assisted the accessing of perspectives and experiences which are all too often unheard (Allen, 2011; Boxall and Ralph, 2009; Morgan and Sengedorj; 2015; Nind et al., 2012).

It was important for the process of the research to establish a position from which it became possible for participants to 'speak' (Adderley et al. 2015; Buckingham, 2009:635, Mitra, 2003; Rudduck \& McIntyre, 2007). So the involvement of children and young people with disabilities and/or other potential barriers to their educational participation, who are often the individuals most subject to policies relating to inclusion (ie. Children and Families Act, 2014; DfE, 2014) were particularly welcomed. In the planning stages it was noted that there may be individuals who might be unable to take the photographs themselves, who would need assistance from others. Boxall \& Ralph (2009:48) discuss this problem, noting that in such circumstances individuals should be enabled to guide and direct 'proxy respondents' to do this, in order that marginalised views and perspectives can be expressed.

In addition to finding a way for all the children and young people to be involved in producing the photographs if they wanted to be, another key ethical dilemma 
revolved around finding a way to share the photographs. It was an essential part of the research to disseminate the photographs taken and gain views on the images from a range of children and young people, to access their reactions and interpretations without giving more value to one view or another. The researchers considered examples in which images of disability are publicly shared, such as BBC 'Ouch!' (2014) and Mencap (2014), but, as noted previously, felt that turning the photographs into cartoons was the best option available.

Harper (2002:19-20) describes photo methodologies as a form of post-modern dialogue that focuses on the authority of the research participant rather than the researcher which can "jolt subjects into a new awareness of their social existence" and bridge "gaps between the worlds of the researcher and the researched". In this case it also enabled a bridging of the gap between different children as they were able to discuss the cartoonised pictures taken by children like them, or reflect on different subject positions from their own and offer their perspectives on what was going on. Although of course, this process brought challenges in terms of ensuring that all voices were heard and respected, which is the focus for the next section of this paper.

\section{Accessing perspectives, respecting differing voices}

The second key ethical issue to be discussed revolved around possibilities for accessing individual's perceptions relating to the concept of inclusion with particular emphasis given to respecting the multiplicity of the 'voices' of children and young people. Clark (2012) and Wall (2017) both utilise visual materials to access differing opinions and attest to the effectiveness and practicality of using such materials to draw out differing perspectives. Clark argues that using photographs to facilitate group discussion invites active rather than passive communication, inviting participants to engage in "collaborative interaction and use their imaginations" (Clark, 2012:229). In 
addition, using a visual methodology which involves annotating images or photographs facilitates the engagement of participants in interpreting their own experiences. Thus, a participatory, visual approach can attend to 'pupil voice' (Allen, 2011; Booth \& Booth, 2003; Hartley \& Allen, 2015; Wall, 2017), enabling children and young people to express 'insider' opinions that might in the past have gone unheard. This can help politically engage children and young people in guiding improvements in school (Adderley et al, 2015; Messiou, 2006, 2012; Rudduck and McIntyre, 2007; Todd, 2012) and start to rework the differential power relationship between the children and young people who are 'included' and the adults who work with them (Hodkinson, 2012; Holt, 2014; Joanou, 2009; Prosser, 2013). In line with this approach, the aim of the research process was not to 'give' a voice to children (a phrase often used in educational contexts) but for children's voices to be shared in a way that other children and adults can access and 'hear' these voices in order to reflect upon the concerns they raise, a subtle but critical distinction. The responses to Figure 3 discussed earlier demonstrate how this sharing and hearing can occur within photo-elicitation research with children. In another example, similar divergent responses were received in response to the image provided in Figure 4.

Figure 4: Photo Record sheet for 'Boy on carpet' image 


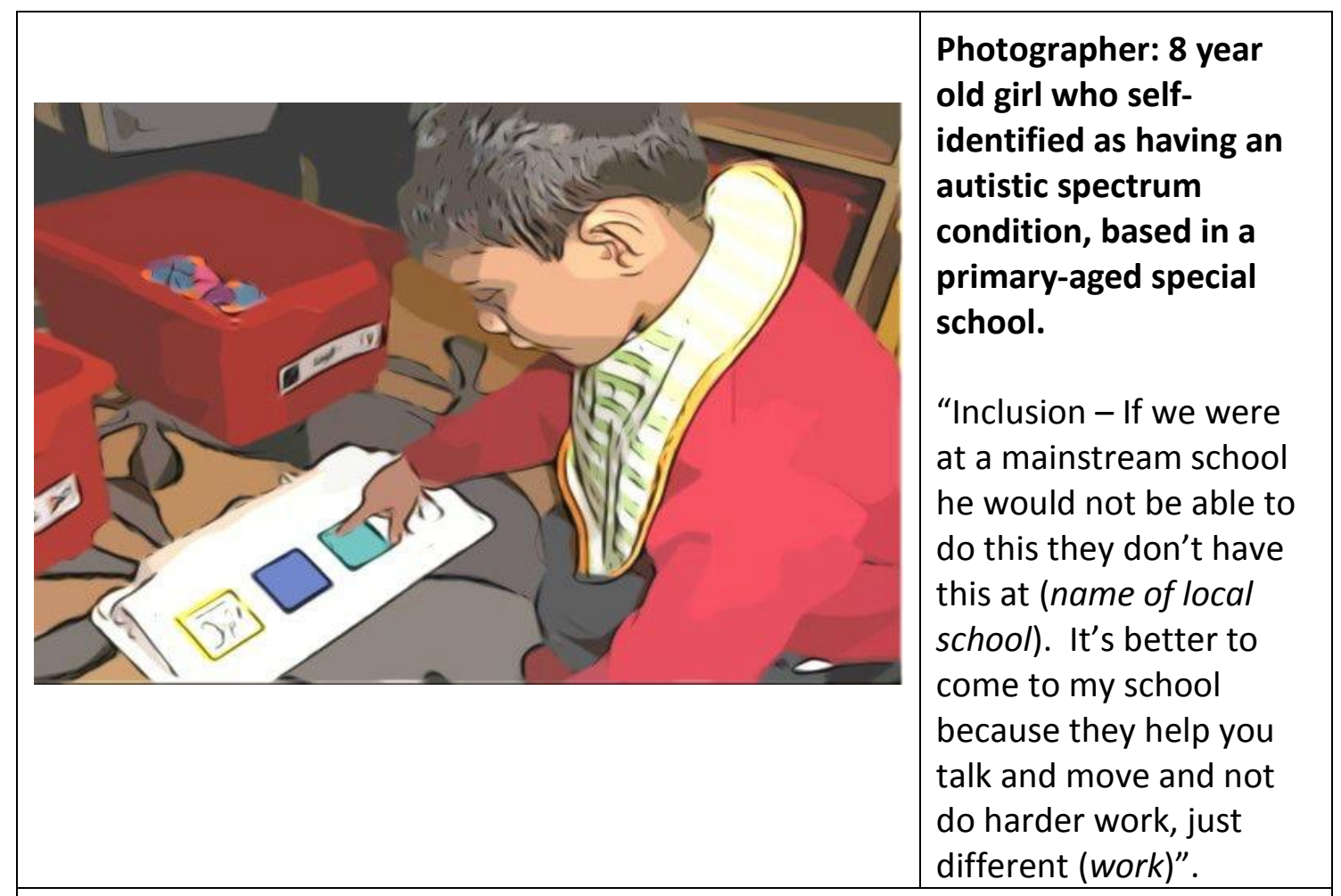

8 year old girl, self-identified as having moderate learning differences, based in a mainstream primary school. "Exclusion - He isn't with the other children and he's wearing a bib even though it isn't lunch time".

9 year old boy self-identified as having Aspergers, based in a mainstream primary school. "I bet he's the only one who has to use a bib. I bet everyone teases him".

10 year old girl self-identified as having moderate learning differences, based in a mainstream primary school. "He seems happy but he's on his own".

The 8 year old photographer of Figure 4 focused on the positive effect of a child having access to equipment and activities that are engaging, perhaps reflecting her own understanding of what appears to be a common practice at her specialist school. In contrast, the wearing of a 'bib' by the child in the image seemed to gain attention from children of a similar age based in a mainstream primary setting. Their comments centred around how the bib might signal the child as different, separate or alone, perhaps because it is a less common sight in the setting they are familiar with. This offers an example of how using photo-elicitation has proved to be a useful, practical and 
effective tool for involving diverse individuals in expressing their views in an honest, differentiated but depersonalised way (Dunne et al, 2017; Hodkinson, 2012), thus offering a safe space for discussion. This can be beneficial for researchers since access to multiple, differing voices can trouble us, leading us away from our 'comfort zone', inviting us to question the contested concept of inclusion and reconsider how children feel about being included (Adderley, 2015; Atkins, 2016; Prosser and Loxley, 2007).

At the same time, the fact that the production of the images and related comments has been guided by children is beneficial for them as they may be reassured that their views about their education are being listened to (Children and Families Act, 2014) and they are able to utilise whichever of their visual as well as verbal communication skills they are most comfortable with when explaining their experiences. This view is supported by Moss et al. (2007) who also adopt visual methodologies when working with similarly aged primary children in Australia. Moss et al. (2007:47) describe visual narrative methodologies as liberatory and empowering; as a way for young pupils to express their knowledge of education, and "give an authentic voice to their concerns and experiences regarding schooling". This approach is 'authentic' because the use of photographs can encourage children to express their feelings, beliefs and opinions, illuminating and challenging the taken-for-granted assumptions made by adults in school settings. Certainly, the intention behind accessing multiple voices, particularly from children with learning needs or disabilities who all too often go unheard (Slee; 2011; Morrgan and Sengedroj, 2015), was to expand understandings of children's conceptions and offer counter narratives that might challenge mainstream stories. Thus, by using photo-elicitation, we hoped to elicit unheard experiences and knowledge about inclusion as a practice and facilitate the sharing of transgressive narratives offered by pupils from 'minority groups'. Integral to this sharing was the involvement of children 
in the process of data analysis, which is the third methodological aspect to be discussed in this paper.

\section{Analysing photographs}

The third key area of concern was the means by which the photographs and the responses to them were analysed. It is rare for children to be involved in data analysis even though they can offer insightful interpretations that researchers can learn from (Cowie and Khoo, 2017). Since the aim was to research how children understand inclusion, it was felt that for ethical reasons, children should be involved in the analysis stage, particularly when a key strength of visual research methods is that they enable "repeat observations and encourages deeper reflection on perception and meaning" (Prosser, 2007:13). Accordingly, the photographers commented on their pictures, and then other children and young people were invited to discuss a substantive, culturally significant theme (inclusion) in relation to the cartoonised images. This provided a route for those involved to engage with and critique the culture or ethos of a school, but also highlight the "unquestioned and unwritten codes of habitual practice" (Prosser, 2007:14) as shown in Figures 2, 3 and 4, and the related comments. The aim of adopting this approach was to enable children and young people to conceptualize and explore their own experiences that might re-inscribe but also interrupt dominant, mainstream discourses. A space was provided within which children were facilitated in reflecting upon and discussing their experiences, and perspectives different to their own (Allen, 2011) so that there might be the opportunity to "paint an alternative picture of an inclusive school" (Whitburn, 2016: 127). One such example of how understanding about another persons' point of view can be encouraged through the process of image analysis is demonstrated in the photographers' and matched comments relating to Figure 5 below: 
Figure 5: Photo Record sheet for 'Snow' image

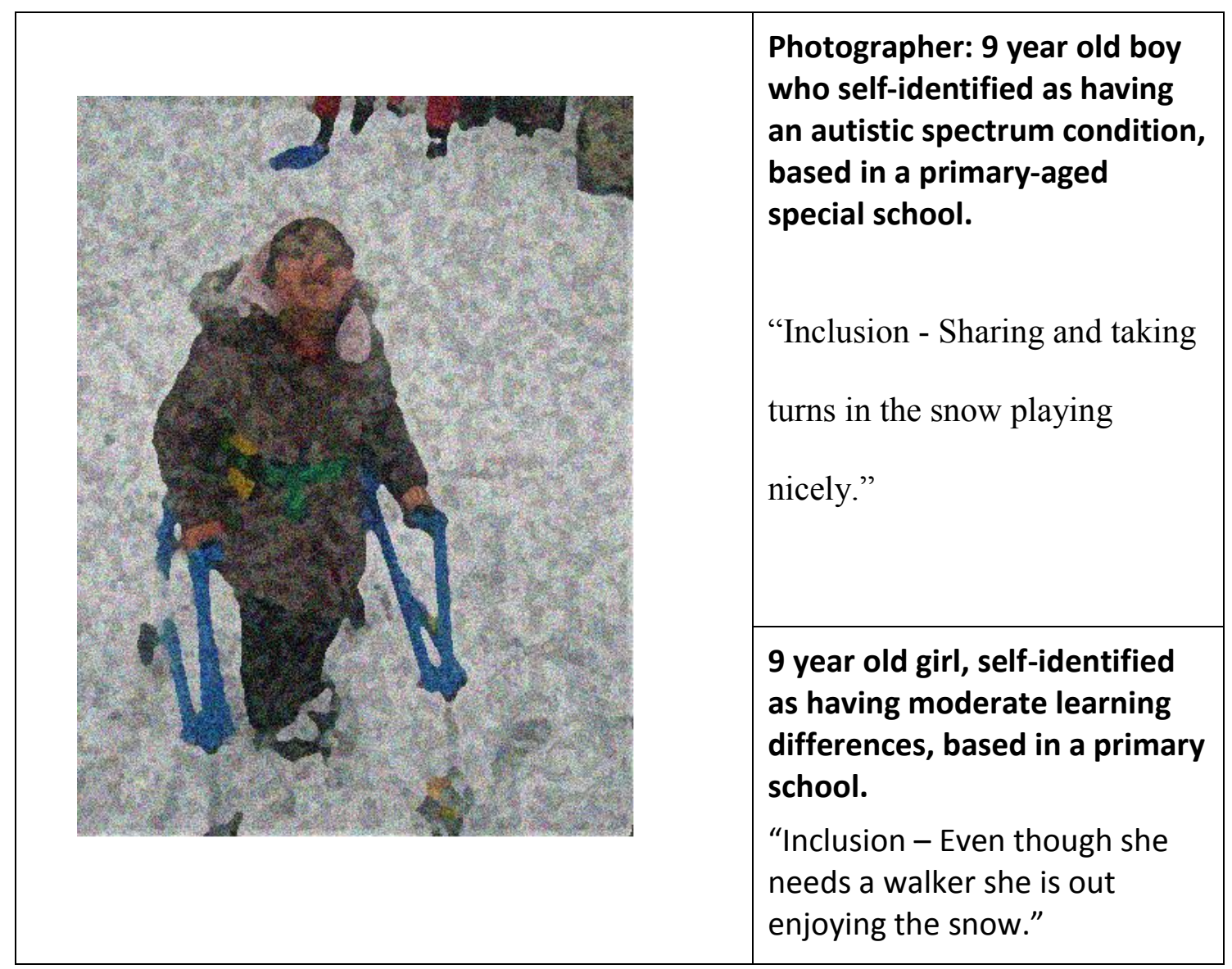

Unlike some of the earlier examples which provided examples of contrasting views, in the case of Figure 5 both the photographer and the child from the matched school, felt the image represented inclusion and identified the child pictured as having a positive experience. While the children's comments were limited to a single statement, it might be inferred that it is in the process of analysing the pictures, not just in taking them, that each child was implicitly invited to draw upon their own memories of playing in the snow and interpret how others might feel about a similar experience. Thus, through the process of data analysis there is an invitation for a sense of self and a sense of empathy towards others to develop. There is also an opportunity for a deeper level of discussion to occur within a class, and for children to share, sometimes for the first time, how they feel about belonging and being included / excluded as encouraged by 
Thomson (2008) and Todd (2012). Certainly, the approach we adopted to image analysis encouraged us to delve deeply into a range of reactions to the same photograph, and on each occasion reflect upon and rethink how views and experiences can be similar or different, whilst also questioning our personal values and beliefs regarding what is conceptualised as inclusive practice.

Revisiting each of the photographs provided a broad range of perspectives, although this is not to suggest that engaging a greater number of participants somehow provides access to a wider or more authentic range of views. Indeed, the photographs were not interpreted as unmediated or authentic representations of self, as they were informed by the framing of the task by the researchers. Rather, the participants' analysis of these images were identified as helping to bridge the gap between the worlds of adults and children. Using photographs actively engaged the children in fun and enjoyable activities, which could help them, their teachers and researchers to explore the lived value and meaning of inclusion, personally and for others. This method also provided an opportunity for positive dialogue between children and the adults around them about their personal view of the world. It offered a chance to expand understandings regarding how to enact inclusion in the context of various settings, highlighting successful practice and the challenges children, young people, practitioners and schools face.

It is a well-rehearsed argument that while photographs can be portrayed as reflections of reality they are, in fact, manipulated, produced socially and staged (Barthes, 1986) by those who produced and annotated them, and by the choices and selections made by researchers (Joanou, 2009). However, this photo-elicitation project did enable the researchers to access in a tangible way, socially constructed understandings of complex issues (Allen, 2011). In sharing and reflecting upon 
photographs, opportunities to inform or challenge stereotypical views of inclusion were created in a non-threatening environment. The sharing of photographs broke the frame of understanding (Harper, 2002), inviting a more reflective stance from those viewing them. This was particularly true in cases where the selected images were felt to be challenging or troubling; images that jumped out or provoked an emotional reaction. Barthes (1984) identifies this troubling experience of an image as 'punctum' and notes that this is important for gauging what an image means to someone. This is of greater relevance when an image provokes strong or contradictory reactions, enabling reflection about the differences, tensions and areas of contention that might be indicated. It infers that those who analyse images can consciously or unconsciously 'script' them, feeling the need to explain or justify the practices shown (Stockall, 2013:320, see also Clarke, 2012; Joanou, 2009; Moss, 2007). In sharing the views of the photographer and garnering the reactions of other children and young people, the intention was to create an ethical, non-threatening, free from judgement framework within which both the concept of inclusion and its enactment within educational settings could be questioned, without valuing one experience or view more than another.

\section{Conclusion}

In the previous section three key ethical aspects that arose from conducting a photoelicitation project with children and young people were explored by positioning children and young people as competent, socially knowledgeable insiders (Cowie and Khoo, 2017; Morgan and Sengedorj, 2015) who can provide insight into the everyday workings of educational inclusion. This was facilitated by the adoption of a participatory and multimodal approach that was pedagogically ethical and inclusive. This method enabled the researchers to access, comprehend and respect a range of experiences and views, while seeking to compensate for unequal power relationships 
between adults and children. Consideration was also given to how involving children and young people in reflecting upon the photographs as part of the data analysis process created space for children, teachers and the researchers to deepen their understanding of experiences alternative to their own. The most difficult aspect of this was disguising the identities of those in the images without obscuring the content, after much trial and error, we feel our approach to 'cartoonising' offers a useful way forward and can be an effective tool when working with photo-elicitation methods.

A photo-elicitation methodology was adopted because photographs can be studied as situated cultural texts; their production is intentional and integrative. In some instances, photographs can represent dominant knowledge, beliefs and values of the society that produce them, evoking a sense of social unity and continuity. However, in the research described in this article, the aim was to access, share, problematise and reflect upon the multiple readings regarding inclusion and inclusionary practices that are possible. Such a view implies that photographs can be studied as sites within which there are struggles over meaning. These struggles can be understood as bound up in relations of power, but as also including the potential for individual viewings (and for research) to politically intervene in the production of understandings regarding, for example, inclusive practices. Within the viewing and discussion of photographs, it is accepted that space is created in which to reiterate but also challenge stereotypes, myths and familiar discourses (Joanou, 2009). Opportunities are provided for creative selfexpression that can reflect upon and evaluate current educational systems, protocols and processes. Such engagement enables an interpreting, rethinking and politicisation of inclusion that is essential for unpicking and addressing the difficulties with advancing inclusive practices in educational contexts around the globe, as many have called for in recent years (Ainscow et al., 2012; Atkins, 2016; Forlin, 2012; Hallett and Armstrong, 
2013; Hodkinson, 2012; Krull et al. 2014; Lauchlan and Greig, 2015; Mitchell, 2014;

Nind et al, 2012; Norwich, 2013; Slee, 2011; Smyth et al. 2014).

While photo-elicitation with children is not without its challenges, some of which

have been discussed here, this method provides a participatory, multimodal route for accessing and sharing multiple and varied voices. These are voices that have often been deprived of a platform to explore their concerns, but they are ones that should be listen to since they speak from 'inside' the experience of educational inclusion.

\section{Acknowledgements}

The research team for the photo-elicitation project consists of four researchers - Linda Dunne, Fiona Hallett, Virginia Kay and Clare Woolhouse (the author of this paper) all of whom work at Edge Hill University.

The team would like to thank the children, young people and schools involved in producing and discussing the photographs, and the teachers, teaching assistants, trainees and academics who took part in the reflection workshops.

\section{References}

Adderley, R.J., Hope, M.A., Hughes, G.C., Jones, L., Messiou, K. and Shaw, P.A., 2015. Exploring inclusive practices in primary schools: focusing on children's voices. European journal of special needs education, 30(1), pp.106-121.

Ainscow, M., Dyson, A., Goldrick, S. and West, M. 2012. Making schools effective for all: rethinking the task, School Leadership \& Management, 32(3) pp.197-213.

Allan, J. 2010. Questions of inclusion in Scotland and Europe. European Journal of Special Needs Education. 25(2) pp.199-208.

Allen, L. 2011. Picture this: using photo-methods in reach on sexuality and schooling. Qualitative Research Journal, 11(5) pp. 487-504.

Armstrong, A. C., Armstrong D. \& Spandagou, I. 2009. Inclusive Education: international policy \& practice. London: Sage.

Atkins, L. 2016. Dis (en) abled: legitimating discriminatory practice in the name of inclusion?. British Journal of Special Education, 43(1), pp.6-21.

Barthes R. 1984. Camera Lucida, London, Harper Collins.

Barthes R. 1986. The Responsibility of Forms, Oxford, Blackwell.

BBC 2014. Ouch Disability News Blog, available at: http://www.bbc.co.uk/news/blogs/ouch/, accessed 31.10.2014.

Booth, T. and Ainscow, M. 1998. From them to us: An international study of inclusion in education. Psychology Press.

Booth, T. and Booth, W. 2003. In the Frame: Photovoice and mothers with learning difficulties, Disability \& Society, 18 (4) pp. 431-442.

Boxall, K. and Ralph, S. 2009. Research ethics and the use of visual images in research with people with intellectual disability. Journal of Intellectual and Developmental Disability, 34 (1) pp. 45-54.

Blyth, M and Solomon, E. 2012. (Eds) Effective safeguarding for children and young people: what next after Munro? Polity Press. 
Carrington, S., Bland, D. and Brady, K., 2010. Training young people as researchers to investigate engagement and disengagement in the middle years. International Journal of Inclusive Education, 14(5), pp.449-462.

Children and Families Act. 2014. (Chapter 3) HMSO, London. Available at: http://www.legislation.gov.uk/ukpga/2014/6/part/3/enacted, accessed 10.11.16.

Clark, J. 2012. Using diamond ranking as visual cues to engage young people in the research process. Qualitative Research Journal, 12 (2) pp. 222-237.

Collier, J., and Collier, M. 1986. Visual anthropology: Photography as a research method. Albuquerque, University of New Mexico Press.

Cowie, B. and Khoo, E. 2017. Accountability through access, authenticity and advocacy when researching with young children, International Journal of Inclusive Education, 21:3, 234-247.

Department for Education (DfE) 2014. Special Educational Needs (SEN) Code of Practice: for 0 to 25 years: Statutory guidance for organisations who work with and support children and young people with SEN, London, DfE.

Dicks, B., Flewitt, R., Lancaster, L. and Pahl, K. 2011. Multimodality and ethnography: working at the intersection. Qualitative Research, 11 (3) pp,227-237.

Dunne, L. 2009. Discourses of Inclusion: a critique. Power and Education, 1(1), pp.4256.

Dunne, L., Kay, V., Hallett, F. and Woolhouse, C. 2017. Visualising Inclusion: Employing a photo-elicitation methodology to explore views of inclusive education, Sage Research Methods Case Studies. http://srmo.sagepub.com/cases

Flewitt, R., 2005. Conducting research with young children: Some ethical considerations. Early child development and care, 175(6), pp.553-565.

Forlin, C. (Eds) 2012. Future directions for inclusive teacher education: An international perspective, London, Routledge.

Hallett F, Armstrong D. 2013. 'I want to stay over': a phenomenographic analysis of a short break/extended stay pilot project for children and young people with Autism. British Journal Of Learning Disabilities. 41(1) pp.66-72.

Harper, D. 2002. Talking about pictures: a case for photo-elicitation. Visual Studies, 17 (1) pp. 13-26.

Hartley, C. and Allen, M. 2015. Symbolic Understanding of Pictures in LowFunctioning Children with Autism: The Effects of Iconicity and Naming. Journal of Autism \& Developmental Disorders, 45 (1) pp.15-30.

Hodkinson, A. 2012. Illusionary inclusion - what went wrong with New Labour's landmark educational policy? British Journal of Special Education, 39 (1) pp.411 .

Holt, L. 2014. The 'voices' of children: De-centring empowering research relations. Children's Geographies, 2(1) pp.13-27.

Joanou, J.P., 2009. The bad and the ugly: Ethical concerns in participatory photographic methods with children living and working on the streets of Lima, Peru. Visual studies, 24(3), pp.214-223.

Kress, G. 2011a. Discourse analysis and Education: A multimodal social semiotic approach, accessed, 07.06.12., available at http://www.linguita.com/a4content/ebooks/discourse/cda.pdf\#page=234,

Kress, G. and van Leeuwen, T. 2001. Multimodal discourse: The modes and media of contemporary communication. London, Arnold.

Krull, J., Wilbert, J. and Hennemann, T. 2014. The social and emotional situation of first graders with classroom behavior problems and classroom learning difficulties 
in inclusive classes. Learning Disabilities: A Contemporary Journal. 12(2): 169190.

Lauchlan, F., and Greig, S. 2015. Educational inclusion in England: origins, perspectives and current directions. Support for Learning. 30(1) pp. 69-82.

MENCAP. 2014. website, available at https://www.mencap.org.uk/?gclid=CJrC9qmj3sECFabLtAodLzsADg, accessed 31.10.2014.

Messiou, K., 2006. Understanding marginalisation in education: The voice of children. European Journal of Psychology of Education, 21(3), pp.305-318.

Messiou, K., 2012. Confronting marginalisation in education: a framework for promoting inclusion. London, Taylor \& Francis.

Mitchell, D. 2014. (Second Edition) What Really Works in Special and Inclusive Education: Using Evidence-based teaching strategies, London, Routledge.

Mitra, D.L., 2003. Student voice in school reform: Reframing student-teacher relationships. McGill Journal of Education, 38(2), pp.289-304.

Morgan, J. and Sengedorj, T., 2015. 'If you were the researcher what would you research?': understanding children's perspectives on educational research in Mongolia and Zambia. International Journal of Research \& Method in Education, 38 (2) pp. 200-218.

Morrow, V., 2008. Ethical dilemmas in research with children and young people about their social environments. Children's geographies, 6(1), pp.49-61.

Moss, J., J. Deppeler, L. Astley and K. Pattison. 2007. Student researchers in the middle: using visual images to make sense of inclusive education. Journal of Research in Special Educational Needs, 7 (1), pp. 46-54.

Nind, M., G. Boorman and G. Clarke. 2012. 'Creating spaces to belong: listening to the voice of girls with behavioural, emotional and social difficulties through digital visual and narrative methods' in International Journal of Inclusive Education, 16 (7, pp. 643-656.

Norwich, B. 2013. Addressing Tensions and Dilemmas in Inclusive Education: Living with Uncertainty, Abingdon, Routledge. 
Nutbrown, C. 2011. Get: Naked by the Pool? Blurring the Image? Ethical Issues in the Portrayal of Young Children in Arts-Based Educational Research. Qualitative Inquiry, 17 (1) pp. 3-14.

Palfrey, J., and Gasser, U. 2013. Born digital: Understanding the first generation of digital natives. Neew York, Basic Books.

Phelan, S.K. and Kinsella, E.A., 2013. Picture this... safety, dignity, and voiceEthical research with children: Practical considerations for the reflexive researcher. Qualitative Inquiry, 19 (2), pp.81-90.

Pope, C., De Luca, R. and Tolich, M. 2010. How an exchange of perspectives led to tentative ethical guidelines for visual ethnography, International Journal of Research \& Method in Education, 33 (3) pp. 301-315.

Prosser, J. 2007. Visual methods and the visual culture of schools. Visual Studies, 22 (1) pp. 13-30.

Prosser, J. and Loxley, A. 2007. 'Enhancing the contribution of visual methods to inclusive education' in Journal of Research in Special Educational Needs, 7 (1) pp. 55-68.

Prosser, J.D., 2013. 'Visual methodology. Collecting and interpreting qualitative materials', in Denzin, N.K. and Lincoln, Y.S. (Eds) Collecting and interpreting qualitative materials, , London, Sage.

Rudduck, J. and McIntyre, D., 2007. Improving learning through consulting pupils. London, Routledge.

Sensoy, O. 2011. Picturing oppression: seventh graders' photo essays on racism, classism, and sexism. International Journal of Qualitative Studies in Education, 24 (3), pp. 323-342.

Slee, R. 2011 The Irregular School: Exclusion, Schooling and Inclusive Education, London, Routledge.

Smyth F, Shevlin M, Ferreira M, et al. 2014. Inclusive education in progress: policy evolution in four European countries. European Journal Of Special Needs Education. November 2014;29 (4) pp.433-445.

Stockall, N. (2013) Photo-elicitation and visual semiotics: A unique methodology for studying inclusion for children with disabilities. International Journal of Inclusive Education, 17 (3) pp.310-328.

Thomson, P. 2008. Doing visual research with children and young people, Taylor and Francis.

Todd, L., 2012. Critical dialogue, critical methodology: bridging the research gap to young people's participation in evaluating children's services. Children's Geographies, 10 (2), pp.187-200.

United Nations (UN). 2006. Convention on the Rights of Persons with Disabilities, available at: http://www.un.org/disabilities/default.asp?id=259, accessed 01.03.2016.

Wall, K., Higgins, S. and Packard, E. 2007. Talking about learning: using templates to find out pupils' views. Devon, England, Soutgate.

Wall, K., Higgins, S., Remedios, R., Rafferty, V. and Tiplady, L. 2013. Comparing analysis frames for visual data sets: Using pupil views templates to explore perspectives of learning. Journal of Mixed Methods Research, 7 (1) pp.22-42.

Wall, K., 2017. Exploring the ethical issues related to visual methodology when including young children's voice in wider research samples. International Journal of Inclusive Education, pp.1316-331. 
Whitburn, B. 2016. Voice, post-structural representation and the subjectivity of 'included' students, International Journal of Research \& Method in Education, 39 (2) pp. 117-130.

Wiles, R., Crow, G. and Pain, H. 2011. Innovation in qualitative research methods: a narrative review. Qualitative Research, 11(5) pp.587-604.

Woolhouse, C., Dunne, L., Hallett, F., and Kay, V. 2017. Perceptions of inclusion. Inclusion Now. Published by Alliance for Inclusive Education (ALLFIE), Spring 2017 (46) pp. 9-11.

Woolner, P, Clark, J., Hall, E., Tiplady, L., Thomas, U. and Wall, K. (2010) Pictures are necessary but not sufficient: Using a range of visual methods to engage users about school design. Learning Environments Research, 13 (1) 1-22.

Young, K.S. and Florian, L., 2013. Researching teacher education for inclusion: Using a methodological memo. International Journal of Research \& Method in Education, 36(4), pp.355-371. 
Appendix 1: guidance text for consent discussion with pupils

\section{Pupil perspectives on Inclusion}

The purpose of this research is to ask pupils and students to take photographs of what they think are examples of inclusion or exclusion.

If someone is unable to take photographs someone else can act as 'director', but we would like the photograph to be the decision of the pupil / student as far as they can describe what picture they would like to take.

Likewise, the written consent form can be completed by an adult (with pupil / student views only please). The photographs should be taken in, and around, school / college and we would like to ask the pupils / students to think about the type of photographs that will make others think twice about what they think being included and excluded is.

We understand that the terms inclusion / exclusion might be difficult to comprehend but we can explain in words that the students will understand. (for example, belonging, left out, welcomed, being made to feel part of the group /school /college etc). i.e. do they feel happy in their class, do they feel like they belong and are asked to join in with games and activities inside and outside the classroom.

Discussing issues around how children feel about being included in school, about belonging and feeling safe can highlight good practices but also raise fears and concerns and highlight some of the problems children face. Learning about these 
experiences can be difficult, but knowing how children feel can help teachers and parents better support them.

All schools and pupils will be anonymised as we want to simply build a bank of images that we can use to explore what we mean by inclusion and exclusion. We ask that you try to include pupils that are representative of your school population in terms of age, gender, learning needs etc and pupils who may not immediately come to mind for such a project (for example those with Visual Impairments) where relevant.

If you are using a disposable camera that we have provided to you, when you return the camera to us please let us know whether you would like prints of the photographs to use within your own school. Please do not remove the sticker from the front of the disposable camera as this indicates that we have pre-paid for postage.

Finally, we will be awarding a prize for the most thought provoking picture in each category (Secondary, Primary, FE , Special School). The winner will be able to select from a range of gift / book tokens. 
Inclusion / exclusion photography record - pupil(s) to complete

Designation of setting (i.e. Secondary / Primary / Special etc)

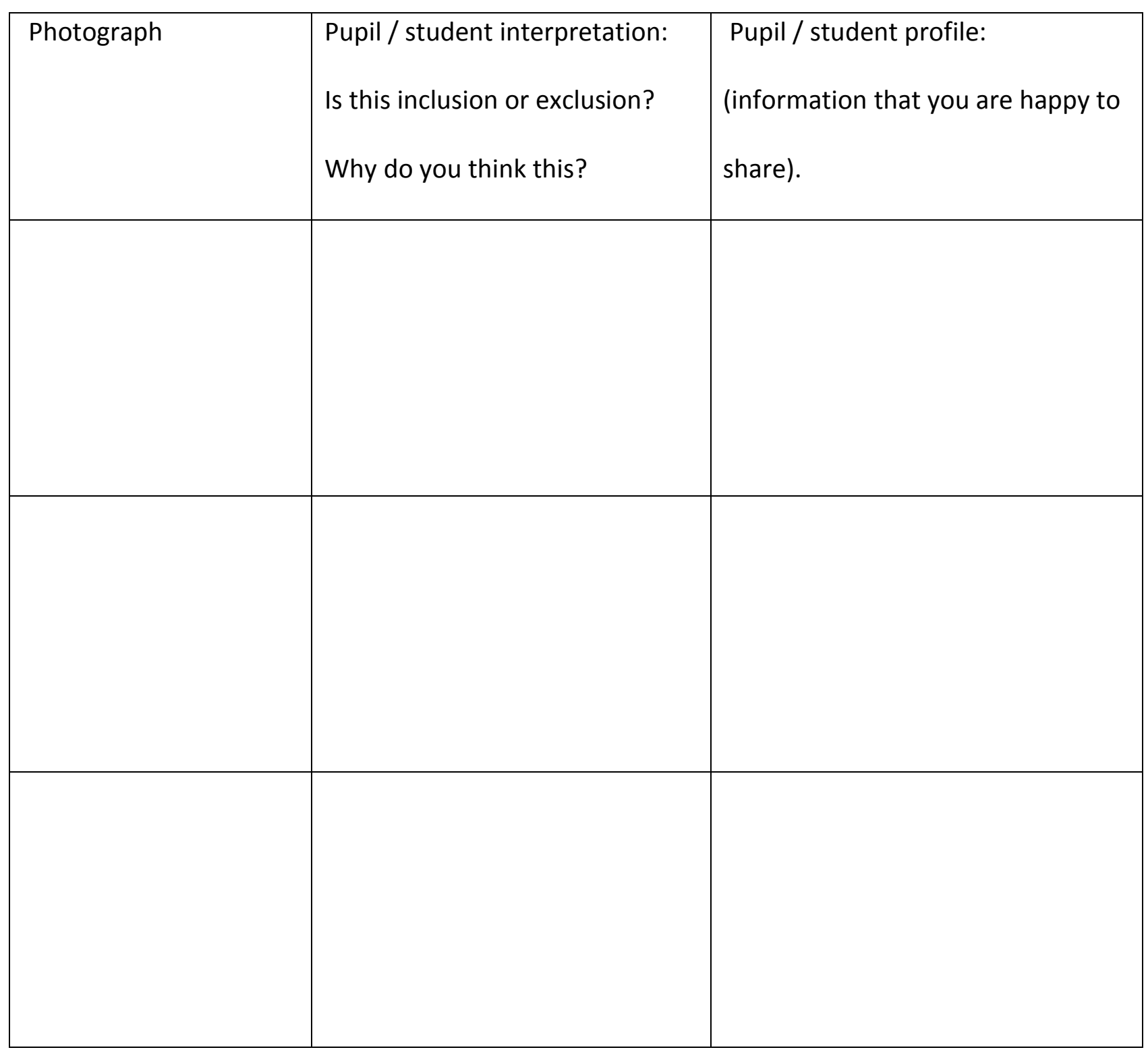


Appendix 2: Summarised photographer record sheets

\begin{tabular}{|c|c|c|}
\hline \multicolumn{3}{|c|}{$\begin{array}{l}\text { Specialist Primary School: } \\
\text { A school in north west England that caters for approximately } 100 \\
\text { children between the ages of } 2-12 \text {, defined as having global learning } \\
\text { difficulties. }\end{array}$} \\
\hline \multicolumn{3}{|c|}{$\begin{array}{l}23 \text { photographs were taken by } 13 \text { pupil photographers whose class } \\
\text { teacher was also the school SENCO: }\end{array}$} \\
\hline Gender & Age & Self-identified as having an SEND \\
\hline Female & 8 & Genetic disorder \\
\hline Male & 8 & Cerebral Palsy \\
\hline Male & 9 & $\begin{array}{l}\text { Moderate learning needs, attending } \\
\text { inclusion link }\end{array}$ \\
\hline Male & 9 & Specific learning need \\
\hline Male & 9 & $\begin{array}{l}\text { Moderate learning needs and } \\
\text { communication difficulties }\end{array}$ \\
\hline Female & 9 & Moderate learning needs \\
\hline Male & 9 & Moderate learning needs \\
\hline Male & 9 & Autistic spectrum condition \\
\hline Male & 10 & Moderate learning needs \\
\hline Female & 10 & Moderate learning needs \\
\hline Female & 10 & $\begin{array}{l}\text { Moderate learning needs and medical } \\
\text { needs }\end{array}$ \\
\hline Male & 10 & Moderate learning needs \\
\hline Female & 10 & Moderate learning needs \\
\hline
\end{tabular}

\begin{tabular}{|c|c|c|}
\hline \multicolumn{3}{|c|}{$\begin{array}{l}\text { Mainstream Secondary School: } \\
\text { A school on the Isle of Man with approximately } 960 \text { pupils on roll } \\
\text { The school offers a range of specialist provision and caters for } \\
\text { pupils aged } 11-18 \text {. }\end{array}$} \\
\hline \multicolumn{3}{|c|}{40 photographs were taken by 9 pupil photographers: } \\
\hline Gender & Age & Self-identified as having an SEND \\
\hline Female & 11 & No \\
\hline Female & 11 & No \\
\hline Female & 12 & No \\
\hline Female & 13 & No \\
\hline Female & 14 & No \\
\hline Male & 15 & Particular learning need \\
\hline Male & 15 & No \\
\hline Female & 16 & Additional educational needs \\
\hline Female & 17 & Autistic spectrum condition \\
\hline
\end{tabular}

